\title{
Saudi Women's Education and Work Opportunities: Equity Matters
}

\author{
Rfah Hadi Alyami \\ Institute of Education: University of Reading, United Kingdom
}

\begin{abstract}
In the context of Saudi Arabia, women are more likely to have fewer work opportunities and a lower income than their male counterparts. Alnajem [1] found that poor Saudi women suffer from a low level of education and lack of employment opportunities. She emphasizes that certain social and cultural factors interact to influence the women's experience as victims of poverty. However, the wave of globalization impacts on women's status; whereby Waterman [2] argues there is a global movement of women, which seems to be aware of the neoliberal discourse to free itself from the economic and politic determinants. This improvement in the economic and social status of women would balance the economic equation. Saudi women are not far from this movement, where many developments have occurred in their status so far. The impact of gender inequality on women's status in Saudi Arabia will be discussed in this paper.
\end{abstract}

\section{Introduction}

In the latter part of the 20th century, significant developments were made in terms of access to education in the Middle East and North Africa (MENA). Moreover, the enrolment of girls in education has increased dramatically in most MENA countries [3]. It is believed that woman is the most influential person in terms of a child's well-being; therefore, an educated woman would be enabled to raise family health issues and prevent diseases, such as AIDS and HIV. Thus, investing in girls' education is one of the most essential elements in the development of society. In addition, educated women are more likely to make claims about their rights and status, alongside the opportunity to choose well-paid jobs [4]. Consequently, women's education is a significant element in the improvement of economic well-being and social development.

Hamdan [5] argues, "Saudi women continually encounter limitations and restrictions at both educational and professional levels. Few women are recently gaining access to pursue professions other than teaching and medicine". Therefore, this paper discusses the educational status of women in Saudi Arabia.
"Inequality...also changes opportunities, incentives, and institutions that form, develop, and transmit characteristics and skills valued in the labor market" [6] would increase the poverty of some disadvantaged groups. Moreover,

It could be argued ...that inequality of opportunity acts for many as a barrier to fulfilling their potential. Those disadvantaged do not forego education because of a lack of incentives in terms of higher pay for the more educated, but because of a range of barriers to their doing so ... A stress on reducing inequality of opportunity leads to policies designed to change the distribution of abilities to compete and to make education more egalitarian; but these policies accept that competition will generate inequalities of income, wealth and outcomes [7]

Competition is one important element in the neoliberal theory, so it has a negative impact on the equality of opportunities.

\section{Women's education in Saudi Arabia}

Before 1960, women in Saudi Arabia received only an informal education. The girls were educated at home to prevent their exposure to society. Some parents sent their daughters only to the school of Kutab (religious schools) where they would learn how to recite the Quran. Others sent their daughters to learn about religion alongside other subjects, so that they may be equipped to be an efficient wife, mother or daughter. These women were prohibited from progressing to higher education [8].

The culture of society and religious leaders found it unacceptable for women to attend schools or colleges at that time $[8,9]$. Al Rawaf and Simmons [8] attribute this situation to Saudi culture during this period, which considered studying unacceptable for women and not in keeping with the religion. Since that time, several schools have been established at a rapid pace; 15 primary schools for girls in 1960/61, increasing to 3370 primary schools, 958 intermediate schools and 415 secondary schools by 1988 . King Saud was moved to establish formal schools in 1959 due to the fact that young, educated Saudi men tended to marry foreign educated women due to the lack of educated Saudi women [8]. 
The first university for women was established in 1979 called Riyadh's King Saud University. It has been established colleges belong to this university offer courses in medicine, nursing, dentistry, education, and public administration. Studying in these colleges and the university is segregated than men campuses, where men has also more opportunity to study different discipline that not provided to women [5].

At that time, the people, politics and, specifically, the ulama (clerics) resisted any change to the education system. Almalki [10] attributes this resistance and the attack on education to the fear of allowing the education sector to compete and contradict the Wahhabi ideology power. This situation existed during the first phase of the Saudi state. "The modern Saudi state emerged in the midst of this difficult situation and its leaders required great wisdom to convince their own people of the importance of education" [11]. The philosophy of the policies and practices in Saudi Arabia stem from the Islamic values and principles and the Wahhabi ideology is the interpretative approach of Shariah law [12].

There was a significant shift in the ulama's attitudes, and those of their religious followers, towards education. This change represented the movement from preventing education in general and women's education in particular to approve and acknowledge the need to educate women, and then moved the stance of those opponents (ulama and their followers) to have the right to control the education[13]. It seems that the shift in the ulama's stance was to safeguard their position of controlling Saudi society. However, Prince Khalid Bin Faisal (the previous Prime Minister of Education) had a plan to prohibit them from holding any significant position in education. He emphasized this in a speech to the media on $26^{\text {th }}$ May 2014:

One of the main reasons for the spread of extreme thought is to give them (extreme leaders) the opportunity in the areas of education and other areas, and the field was all for them, and there is no field to the thought of the Saudi, who has a Moderation Approach. We abandon our children and they kidnapped them. The Kingdom of Saudi Arabia exists between two severe currents; the power of extremism ideology and the atheistic current. These have flanked the Arab and Islamic region as a whole. There are those who disbelief the society and those who try to abandon Islam; no doubt these affect us in the Kingdom. This conflict found a vacuum in the Kingdom, because we are all in the arena; we left the arena to them. In schools too, the arena has been left to them.... Islam does not reject urbanization, modernization, systems development, development in the curriculum, development in everyday life, nor any development in construction, urban planning and the reconstruction of all kinds of life. We must build our civilization and our trendy gains on our principles and Islamic rules... to build the future of this country and build the personal youth of this country based on Islamic principles and values, taking advantage of all the achievements of the modern era; this is what we are seeking now in the Ministry of Education [14].

This speech reflects the real need of reforming education policy in Saudi Arabia. It suggests the tendency to change the country's philosophical education framework. Therefore, the challenges facing women would be the major concern as a result of this dominance.

Conversely, providing education to women is essential to societal development. Moreover, it could contribute to improving family health and reducing child and female mortality rates. For example, UNESCO [15] argues that in low-income countries:

If all women completed primary education in these countries, the under-5 mortality rate would fall by $15 \%$. If all women completed secondary education, it would fall by $49 \%$, equal to around 2.8 million lives a year... If all women completed primary education, there would be $66 \%$ fewer maternal deaths, saving 189,000 lives per year. In sub-Saharan Africa alone, if all women completed primary education, there would be $70 \%$ fewer maternal deaths, saving 113,400 women's lives [15].

Therefore, a link exists between women's education and general health; either mental or physical well-being. In turn, this will contribute to raising social awareness. AlMunajjed [16] asserts that, as a result of developing education, Saudi women have experienced improvements in many aspects of their social life; fertility and mortality rates have reduced, the number of females in the workplace has increased and improvements have been made in terms of health and nutrition.

Interestingly, further developments have been made in an attempt to raise the status of women in Saudi Arabia. According to Blanchard [17]:

King Abdullah recognized women's right to vote and stand as candidates in the 2015 municipal council elections and expanded the size of the national Shura Council to include 30 women in the 2013 session. These moves, while controversial in the kingdom, have been seen by some outsiders as signs that managed, limited political and social reforms are possible [17].

"This development provides ... opportunities to women and plays an important role in realizing equity between the two sexes in job opportunities" [18]. It also demonstrates a significant shift in the 
policy and attitudes towards women in the Saudi Arabian context.

Another encouraging reform in Saudi Arabia is the appointment of Mrs. Noura Al-fayez in 2009 to the position of Vice-Minister of Education, a position traditionally held by males in this Ministry $[18,19]$. She became the first Saudi woman to direct the education of girls. It is hoped that this shift will lead to changes in girls' education; for example, allowing girls to participate in sports activities at school. Mathis [20] argues that in order to achieve educational reform, it is necessary to understand the role of female principals in government schools and investigate their perspectives of their role to inform improvement and changes in their schools. This would raise awareness of girls' educational needs; something that, historically, has been ignored by male leaders. Mathis [20] conducted a qualitative study that concerned with the educational leadership of females in Saudi Arabia. This study was a descriptive research of Saudi female principals in the eastern region. The purpose of this study was to explain the role of the leadership female and their perspective of this role in Eastern Province. She concludes that the principals of schools (12 principals of primary, intermediate and secondary school) do not have enough autonomy to act or to make decision; they describe their role as a manager rather than being leader. Therefore, any hoped change would be difficult to be achieved.

\section{Leading educational change}

Change is a derivative of the verb "to change", which means "to alter or modify". Change is a term used frequently in the literature; however, to date, there is no consensus on a definition. Flamholtz and Randle [21] assert that this concept remains fragmented in the literature and needs to be defined from both scholar and practitioner perspectives. However, some authors have provided a general definition. "Change" is understood widely as referring to a shift from the current point of balance to the target point of balance; thereby, moving from one state to another in space and time [22].

The constant change in all life aspects is considered one of the most striking features of the contemporary world, as imposed on modern management; a reality that has become a tool with which to create and manage change in the first place. The capability to manage change requires the ability to innovate, create and develop strategies for change [23].

Education is facing significant challenges in societies that were not considered by those in charge of the educational process. These challenges affect all aspects of educational work, and provide motivation to initiate continuous change; thereby, placing educational work close to its requirements, community and global developments. Amid these challenges, educational leaders may encounter many obstacles, as they are not working in isolation from contemporary life; rather, they work within these events to nurture generations armed with science. They can contribute to creating nations that are able to co-exist and keep pace with human development [24].

Therefore, it is important to consider two elements when reforming education in the Saudi context. First, the Saudi culture has been labeled conservative and maintained, which stems from the principles of Islamic customs and values. The second issue refers to Saudi society's attitude towards women; women are more likely to have limited opportunities in the workplace and education in Saudi Arabia. "We must also recognize, however, that culture changes over time; this explains some of the swings towards and away from issues of corporate responsibility which we have seen over the past four decades... Changes in the treatment of and attitudes towards women and their abilities in the workplace is something which we have seen develop gradually" [25].

A study conducted by Metcalfe [26] focused on the gender issues evident in three Arab Gulf countries; Saudi Arabia, Bahrain and UAE. This study attempts to address a number of issues. One of these attempts to answer the following question: how can national and institutional Human Resource Development (HRD) frameworks support women's empowerment and education development? Findings from this study suggest that Arab women should be maintained to improve feminist agency and build their own forms of Islamic feminism, which can be relevant to their own empowerment agenda [26]. The political reform concerned with women's education has been further emphasised in UAE during the period 1938 to 2007. This has afforded women the right to access education and equal opportunities in all professions since 1971 [27]. Yet, compared with other women worldwide, Saudi women do not have access to all professions. Issan [28] attributes this limiting of work opportunities to the rule of Wahhabi doctrine; whereby women should not be in direct contact with men. This restriction has led to few professions offering positions to women; those that do comprise mostly teaching in schools and nursing in hospitals.

However, Aksornkool [29] argues the importance of making a supportive political decision to empower women's status. It is insufficient on a large scale to empower women only in education, as this political decision would create a regulation that impacts on society's attitude towards women and accelerates their empowerment.

The following Figures illustrate the discrepancy between the literacy rates of male and female adults in Saudi Arabia for the period 1992 to 2015. 
Although improvement has been observed in both rates, there remains a difference in recent trends in favour of males. However, the gap between both genders in the youth generation is not significant, although males are still favoured. Undoubtedly, these literacy gaps will create gender inequality in work opportunities and income levels.

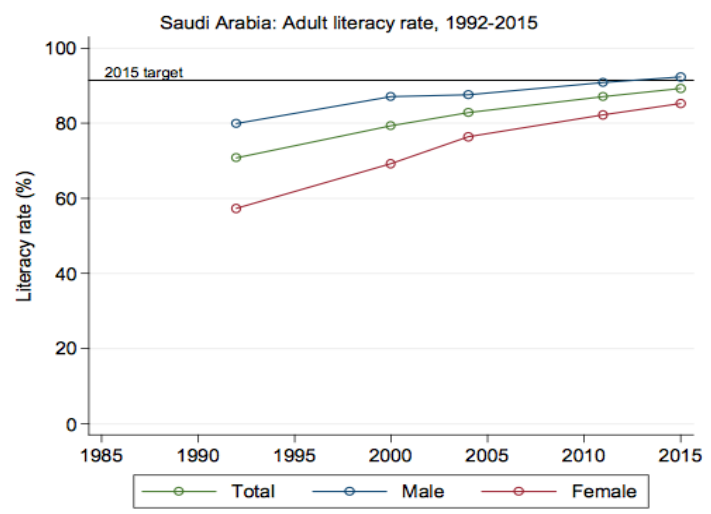

Figure 1. Adult literacy rate

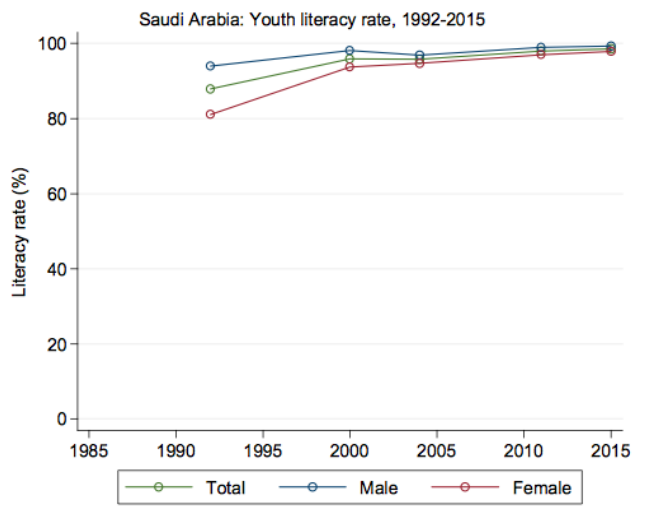

Figure 2. Youth literacy rate

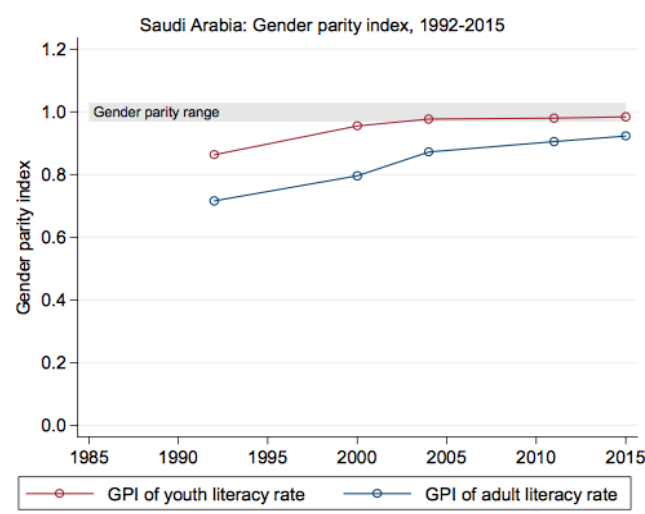

Figure 3. Gender parity index

Source: UNESCO Institute for Statistics, May 2013
The best explanation of having issue in girls literacy is explained by Hamdan [5], where she stated that "there is no law in the country, as yet, that prohibits male guardians (for example, father or brother) from taking girls out of school, no law making education mandatory to high school...There is also no law to determine the age at which girls can marry" [5]. Therefore, this issue needs to be addressed to achieve equality in education for all.

The National Strategy for the Development of Education Project' was established by Tatweer Project based on many principles [31]. One of these principles is associated with opportunities to ensure equal learning and education for all students regardless of gender or social background or levels of abilities. As a result, the aim is to improve girls' education to achieve gender equity. Offering new disciplines in higher education for girls and empowering them in the labour force would support this improvement.

\section{Conclusion}

There is a significant shift in the policy and attitudes towards women in the context of Saudi Arabia. The awareness of the importance of women education and status has been raised by the royal government; King Abdullah recognises women's right to stand as candidates in the municipal council elections. The appointment of Mrs. Noura Al-Fayez in 2009 as the first Saudi woman to direct the education of girls is another change instigated by King Abdullah. In addition, Prince Khalid Bin Faisal intended to prevent extremist leaders who oppose women's rights from holding any significant position in education. These movements and official decisions would change the treatment of, and attitudes towards, women and serve to empower their feminist agency. However, based on the studies and figures presented in this paper, women still do not have the opportunities to access all professions, and literacy rates continue to favour males.

\section{References}

[1] Alnajem, M., Woman poverty characteristics in the Saudi Societies, in Social scinces. 2012, King Saud University: Riyadh

[2] Waterman, P., Globalization, Social Movements and the New Internationalisms. 2001, London and Washington: Mansell.

[3] Roudi-Fahimi, F. and V.M. Moghadam, Empowering Women, Developing Society: Female Education in the Middle East and North Africa. Population Reference Bureau, 2003.

[4] DFID, Girls' education: towards a better future for all. 2005: Department for International Development. 
[5] Hamdan, A., Women and education in Saudi Arabia: Challenges and achievements. International Education Journal, 2005. 6(1): p. 42-64.

[6] Corak, M., Income Inequality, Equality of Opportunity, and Intergenerational Mobility. Journal of Economic Perspectives, 2013. 27(3): p. 79-102.

[7] Saad-Filho, A. and D. Johnston, Neoliberalism: A critical Reader 2005, London Pluto Press.

[8] Al Rawaf, H. and C. Simmons, The education of women in Saudi Arabia. Comparative Education. Taylor and Francis, Ltd, 1991. 27 (3): p. 287-295.

[9] Roy, D.A., Saudi Arabia education: Development policy. Taylor \& Francis, 1992. 28(3): p. 477-508.

[10] Almalki, H., Preacher and is not a prophet: a critical reading of the doctrine of Sheikh Mohammed bin Abdul Wahab in atonement. 2004, Amman Dar Alrazi

[11]Bubshait, A.-J., Saudi Women's Education: History, Reality and Challenges, in Woman in Saudi Arabia Cross Cultural Views. 2008, Ghainaa Publications.

[12] Alshyeb, J., Religious diversity management in Saudi Arabia. 2013: Afaq Center for Research \& Studies. Available online on http://aafaqcenter.com/page/87.

[13] Alsadhan, A., The ideology of Saudi society and the change: Reading in the book of resistance the change in Saudi society: Opening Schools girls' education as a model. Albian 2012. 299.

[14] MoE. The Press conference of the Prince Khalid AlFaisal on the development of education on 26 May 2014 available 2014 June 4, 2014].

[15] UNESCO, Teaching and Learning: Achieving quality for all. Education for All Global Monitoring Report 2013/4. 2014, UNESCO

[16] AlMunajjed, M., Women's Education in Saudi Arabia: The Way Forward. . n.d: The Ideation Center: Generating ideas for Middle East. Retrived from http://www.ideationcenter.com/ideation_research/ideation_ article/47143812.

[17] Blanchard, C.M., Saudi Arabia: Background and U.S. Relations, in Congressional Research Service. 2014.

[18] MOHE, Women in Higher Education: Saudi Initiatives \& Achievements 2010, Riyadh: Ministry of Higher Education.

[19] IHS, Saudi Arabia's King changes the guard. Jane's. Available online http://carnegieendowment.org/files/ IAA_6_June_pxx_Saudi_Arabia2.pdf, 2009.

[20] Mathis, B., Educational leadership: a description of Saudi female principals in the eastern, in Education. 2010, the Faculty of the Graduate College of the Oklahoma State University Oklahoma State.
[21] Flamholtz, E. and Y. Randle, leading strategic change. 2008, United States of America Cambridge University Press.

[22] Assayed, O., change management powers in the twenty first century 2004, Almansorah: Dar Alwafa.

[23] Atawy, E., educational management and supervision. 2004, Amman: Dar Althaqafah.

[24]Abuabed, M., Modern trends in the effective educational leadership. 2005, Amman Dar Alamal.

[25] Hannagan, T., Management Concepts \& Practices. Fourth ed, ed. F. edition. 2005, England: Pearson Education Limited.

[26] Metcalfe, B.D., Women, empowerment and development in Arab Gulf States: a critical appraisal of governance, culture and national human resource development (HRD) frameworks. Human Resource Development International, 2011. 14(2): p. 131-148.

[27]Bilkhair, A., Political Reforms for Access and Equity: Women's Education in the United Arab Emirates, from 1938 to the Present. On Campus With Women, 2007. 36(3): p. 6.

[28] Issan, S.A., Gender and Education in the Arabian Gulf States in Education in the Broader Middle East: borrowing a baroque arsenal G. Donn and Y. Almanthri, Editors. 2013, Symposium Books: Oxford.

[29] Aksornkool, N., Educate to empower: An Asian experience in Women, Education and Empowerment: Pathways towards Autonomy. Report of the International Seminar held at UIE, Hamburg, 27 January - 2 February 1993, C. Medel-Anonuevo, Editor. 1995, UNESCO Institute for Education.

[30] UIS, Adult and Youth Literacy: National, Regional and Global trends, 1985-2015 2013, Canada UNESCO Institute for Statistics.

[31] King Abdulla Bin Abdul-Aziz Project for Public Educational Development, 2011. King Abdulla Bin AbdulAziz Project for Public Educational Development, ed. T. Project. Riyadh: King Abdulla Bin Abdul-Aziz Project for Public Educational Development. 